Arch. Vet. Scienc. 3(1):39-44, 1998

Printed in Brazil

\title{
ESTUDO RETROSPECTIVO DAS NEOPLASIAS DIAGNOSTICADAS EM ANIMAIS SELVAGENS OU EXÓTICOS PELO SERVIÇO DE PATOLOGIA DO HOSPITAL VETERINÁRIO DA UNIVERSIDADE FEDERAL DO PARANÁ ENTRE 1974 E 1996
}

\author{
PEDRO RIBAS WERNER ${ }^{1}$; MÁRCIO CHIQUITO ${ }^{2}$; JOSÉ RICARDO PACHALY ${ }^{1}$ \\ ${ }^{1}$ Universidade Paranaense - UNIPAR - Umuarama-PR. ${ }^{2}$ Curso de Pós-Graduação em Ciências Veterinárias, \\ Universidade Federal do Paraná.
}

\begin{abstract}
From 1974 to 1996, 28 cases of neoplasia were diagnosed in wild or exotic animals at the Service of Animal Pathology, Veterinary Hospital, Federal University of Paraná - Brazil, comprising $2.88 \%$ of all neoplasia diagnosed during that period. Eighteen cases (66.7\%) occurred in mammals (six hamsters, four mice, two rabbits, one agouti, one guinea pig, one capuchin monkey, one manned wolf, one puma and one lion). Nine cases (33.3\%) were diagnosed in birds (two domestic canaries, two amazon parrots, two budgerigars, one white-faced whistling-duck, one black lory and one rufous-bellied thrush). Seventeen cases (60.7\%) were of malignant neoplasia: six lymphosarcomas, three epidermoid carcinomas, three undifferentiated carcinomas, one fibrosarcoma, one hemangiosarcoma, one undifferentiated sarcoma, one seminoma, one sebaceous gland adenocarcinoma, and one undetermined adenocarcinoma. Benign neoplasia totaled nine cases (32.1\%): two hemangiomas, two lipomas, two fibromas, one hepatocelular adenoma, one papilloma and one trichoepithelioma. Additionally, two basal cell carcinomas were diagnosed. These were considered as locally aggressive, rather than malignant neoplasms.
\end{abstract}

Key Words: Neoplasia, animal pathology, wild animals, exotic animals.

RESUMO - Dentre 970 casos de neoplasias diagnosticados entre abril de 1974 e março de 1996 no Serviço de Patologia do Hospital Veterinário da Universidade Federal do Paraná, 28 casos $(2,88 \%)$ ocorreram em animais selvagens ou exóticos. Dezoito desses animais eram mamíferos (seis hamsters, quatro camundongos, dois coelhos, uma cutia, uma cobaia, um macaco prego, um lobo guará, um puma e um leão) e 9 eram aves (dois canários belgas, dois papagaios, dois periquitos australianos, uma marreca irerê, um lóris negro e um sabiá laranjeira). Destes, 17 casos (60,7\%) eram de neoplasias malignas, sendo seis linfossarcomas, três carcinomas espinocelulares, três carcinomas indiferenciados, um fibrossarcoma, um hemangiossarcoma, um sarcoma indiferenciado, um seminoma, um adenocarcinoma de glândula sebácea e um adenocarcinoma indeterminado. As neoplasias benignas somaram nove casos (32,1\%), sendo dois hemangiomas, dois lipomas, dois fibromas, um adenoma hepatocelular, um papiloma e um tricoepitelioma. Além disso, registraram-se dois casos $(7,0 \%)$ de carcinomas basocelulares, considerados mais como localmente agressivos do que como malignos.

Palavras-Chave: Neoplasia, patologia veterinária, animais selvagens, animais silvestres.

\section{Introdução}

A clínica médica e cirúrgica de animais exóticos e selvagens vem adquirindo crescente importância na prática veterinária moderna. Com o objetivo de contribuir para o conhecimento das neoplasias que acometem tais animais, realizou-se um levantamento nos arquivos do Serviço de Patologia do Hospital Veterinário da Universidade Federal do Paraná desde 1974, ano em que se implantou aquele sistema de registros. Os dados obtidos foram analisados, estabelecendo-se a prevalência das neoplasias registradas e transcrevendo-se algumas observações julgadas importantes dentre as constantes nas fichas de encaminhamento do material para diagnóstico.

\section{Material e Métodos}

Pesquisaram-se os dados dos arquivos dos Serviços de Patologia Animal e de Medicina de Animais Selvagens e Odontologia Veterinária do
Hospital Veterinário da Universidade Federal do Paraná (HV-UFPR), onde se fez um levantamento de todas as neoplasias de animais selvagens e exóticos diagnosticadas entre abril de 1974 e março de 1996. As neoplasias em questão chegaram ao Serviço de Patologia na forma de peças de biopsia ou necropsia, obtidas por veterinários do Zoológico de Curitiba, da iniciativa privada de Curitiba e do próprio HVUFPR.

Os dados recolhidos desses arquivos foram computados e são apresentados sob a forma de tabelas, incluindo-se, quando possível, informações ou comentários julgados pertinentes.

As neoplasias foram classificadas como benignas, malignas ou localmente agressivas.

\section{Resultados}

Das 970 neoplasias diagnosticadas entre abril 
de 1974 e março de 1996 no Serviço de Patologia do HV-UFPR, 28 (2,88\%) ocorreram em animais selvagens ou exóticos. Estes dados estão sumariados na Tab. 1, que apresenta a distribuição dessas neoplasias entre as espécies estudadas.

Tabela 1. Distribuição, segundo a espécie, dos casos de neoplasia diagnosticados em animais selvagens ou exóticos pelo Serviço de Patologia do Hospital Veterinário da Universidade Federal do Paraná, entre abril de 1974 e março de 1996.

\begin{tabular}{l|c}
\multicolumn{1}{c|}{ Espécie } & Número de casos \\
\hline Hamster (Mesocricetus auratus) & 6 \\
Camundongo (Mus musculus) & 4 \\
Canário belga (Serinus canarius) & 2 \\
Coelho (Oryctolagus cuniculus) & 2 \\
Papagaio (Amazona sp.) & 2 \\
Periquito australiano (Melopsitacus undulatus) & 2 \\
Leão (Panthera leo) * & 1 \\
Cobaia (Cavia porcellus) & 1 \\
Macaco prego (Cebus apella) & 1 \\
Cutia (Dasyprocta azarae) & 1 \\
Lobo guará (Chrysocion brachyurus) & 1 \\
Puma (Puma concolor) & 1 \\
Marreca irerê (Dendrocygna viduata) & 1 \\
Sabiá-laranjeira (Turdus rufiventris) & 1 \\
Lóris negro (Chalcopsitta atra) & 2 \\
\hline
\end{tabular}

* Refere-se a um animal portador de neoplasias de dois diferentes tipos histológicos.

\section{NEOPLASIAS BENIGNAS}

As neoplasias benignas totalizam nove casos $(32,1 \%)$ do total de neoplasias em animais selvagens ou exóticos. A distribuição das neoplasias benignas entre os mamíferos está resumida na Tab. 2, enquanto a Tab. 3 traz a distribuição entre as aves. Finalmente, a Tab. 4 apresenta a distribuição geral segundo o sítio de ocorrência e, logo a seguir, apresentam-se informações adicionais quanto aos casos de neoplasia benigna diagnosticados no período.

Tabela 2. Distribuição, segundo a espécie, dos casos de neoplasia benigna diagnosticados em mamíferos selvagens ou exóticos pelo Serviço de Patologia do Hospital Veterinário da Universidade Federal do Paraná entre abril de 1974 e março de 1996.

\begin{tabular}{lccccccc}
\hline Tipo Histológico & \multicolumn{7}{c}{ Espécie } \\
\cline { 2 - 7 } & Hamster & Cobaia & Cutia & Macaco & Puma & Leão & Total \\
\hline Hemangioma & 1 & - & 1 & - & - & - & 2 \\
Tricoepitelioma & - & 1 & - & - & - & - & 1 \\
Fibroma & - & - & - & 1 & - & - & 1 \\
Adenoma hepatocelular & - & - & - & - & 1 & - & 1 \\
Lipoma & - & - & - & - & - & 1 & 1 \\
Papiloma & - & - & - & - & - & 1 & 1 \\
\hline
\end{tabular}

Tabela 3. Distribuição, segundo a espécie, dos casos de neoplasia benigna diagnosticados em aves selvagens ou exóticas pelo Serviço de Patologia do Hospital Veterinário da Universidade Federal do Paraná entre abril de 1974 e março de 1996.

\begin{tabular}{lcc}
\hline Tipo Histológico & \multicolumn{2}{c}{ Espécie } \\
\cline { 2 - 3 } & Periquito & Papagaio \\
\hline Fibroma & 1 & - \\
Lipoma & - & 1 \\
\hline Total & 1 & 1 \\
\hline
\end{tabular}


Tabela 4. Distribuição, segundo o sítio, dos casos de neoplasia benigna diagnosticados em animais selvagens ou exóticos pelo Serviço de Patologia do Hospital Veterinário da Universidade Federal do Paraná entre abril de 1974 e março de 1996.

\begin{tabular}{lcc}
\hline Sítio & \multicolumn{3}{c}{ Número de casos } \\
\cline { 2 - 3 } & Aves & Mamíferos \\
\hline Pele e Subcutâneo & 1 & 4 \\
Cavidade oral & - & 1 \\
Fígado & - & 1 \\
Não especificado & 1 & 1 \\
\hline
\end{tabular}

Informações adicionais quanto às neoplasias benignas.

Hemangioma - Diagnosticado no membro torácico de um hamster, fêmea, de dois anos de idade, e em uma cutia.

Fibroma - Foram diagnosticados dois casos, um no tecido subcutâneo de um macaco prego, próximo ao maléolo da tíbia, e outro em um periquito australiano.

Lipoma - Foi encontrado um caso no tecido subcutâneo de um leão, macho, de 12 anos de idade, e um na região da cloaca de um papagaio.

Adenoma hepatocelular - Ocorreu no fígado de um puma de 18 anos, macho.

Tricoepitelioma - Ocorreu na região toraco- lombar de uma cobaia de sete anos, fêmea. Tratavase de um tumor restrito ao tegumento, ulcerado e, internamente, multilobulado.

Papiloma - Removido da cavidade oral do mesmo leão citado na referência ao lipoma.

\section{NEOPLASIAS MALIGNAS}

Neoplasias malignas compreenderam $60,7 \%$ dos diagnósticos (17 casos). As Tabelas 5 e 6 apresentam a distribuição dessas neoplasias entre aves e mamíferos. A Tab. 7 traz a distribuição das neoplasias malignas por sítio de ocorrência. Excluiu-se desta pesquisa um caso de melanocarcinoma ocorrido no pescoço de um pássaro não identificado.

Tabela 5. Distribuição, segundo a espécie, dos casos de neoplasia maligna diagnosticados em aves selvagens ou exóticas pelo Serviço de Patologia do Hospital Veterinário da Universidade Federal do Paraná entre abril de 1974 e março de 1996.

\begin{tabular}{lcccccc}
\hline Tipo Histológico & \multicolumn{5}{c}{ Espécie } \\
\cline { 2 - 6 } & Canário & $\begin{array}{c}\text { Periquito } \\
\text { australiano }\end{array}$ & $\begin{array}{c}\text { Marreca } \\
\text { irerê }\end{array}$ & $\begin{array}{c}\text { Lóris } \\
\text { negro }\end{array}$ & Sabiá & Papagaio \\
\hline Carcinoma espinocelular & - & - & - & - & 1 & 1 \\
Carcinoma indiferenciado & - & - & 1 & - & - & - \\
Sarcoma indiferenciado & 1 & - & - & - & - & - \\
Linfossarcoma & - & - & - & 1 & - & - \\
Seminoma & - & 1 & - & - & - & - \\
\hline Total & 1 & 1 & 1 & 1 & 1 & 1 \\
\hline
\end{tabular}

Tabela 6. Distribuição, segundo a espécie, dos casos de neoplasia maligna diagnosticados em mamíferos selvagens ou exóticos pelo Serviço de Patologia do Hospital Veterinário da Universidade Federal do Paraná entre abril de 1974 e março de 1996.

\begin{tabular}{lcccc}
\hline Tipo Histológico & \multicolumn{5}{c}{ Espécie } \\
\cline { 2 - 5 } & Hamster & Coelho & Lobo guará & Camundongo \\
\hline Linfossarcoma & 3 & 1 & - & - \\
Fibrossarcoma & 1 & - & - & - \\
Carcinoma indiferenciado & - & - & 1 & - \\
Hemangiossarcoma & - & - & - & 1 \\
Adenocarcinoma de glândula sebácea & - & - & - & 1 \\
Carcionoma espinocelular & - & 1 & - & 1 \\
Adenocarcinoma & - & - & - & 1 \\
\hline Total & 4 & 2 & 1 & 4 \\
\hline
\end{tabular}


Tabela 7. Distribuição, segundo o sítio de ocorrência, dos casos de neoplasia maligna diagnosticados em animais selvagens ou exóticos pelo Serviço de Patologia do Hospital Veterinário da Universidade Federal do Paraná entre abril de 1974 e março de 1996.

\begin{tabular}{lcc}
\hline Sítio & \multicolumn{2}{c}{ Número de casos } \\
\cline { 2 - 3 } & Mamíferos & Aves \\
\hline Pele e tecido subcutâneo & 5 & 2 \\
Cavidade peritoneal & 1 & 1 \\
Timo/Linfonodos & 2 & - \\
Cavidade oral & - & 1 \\
Músculos & 1 & 1 \\
Gônadas & - & 1 \\
Crânio & 1 & - \\
Generalizado & - & 1 \\
\hline Total & 10 & 7 \\
\hline
\end{tabular}

Informações adicionais quanto às neoplasias malignas.

Linfossarcoma - Foi diagnosticado em três hamsters, localizados no timo, na cabeça e no pescoço, respectivamente. A ficha deste último animal mencionava histórico clínico de diarréia crônica, sendo que, à necropsia, encontraram-se metástases no fígado, baço e coração. A mesma neoplasia acometeu um coelho sem raça definida, macho, de sete anos, localizando-se nos linfonodos, e um lóris negro, macho, sob a forma generalizada.

Fibrossarcoma - Foi encontrado nos músculos torácicos de um hamster.

Carcinoma indiferenciado - Ocorreu na cavidade peritoneal de um lobo guará, macho, e na cavidade celomática de uma marreca irerê.

Carcinoma espinocelular - Foi diagnosticado na pele de um coelho, macho, sem raça definida, de seis anos de idade, na asa de um canário macho, na região da cloaca de um sabiá-laranjeira e na língua de um papagaio de 20 anos de idade.

Seminoma - Ocorreu no testículo esquerdo de um periquito australiano adulto, provocando grande aumento do volume abdominal.

Hemangiossarcoma - Ocorreu no tecido subcutâneo da região esternal de um camundongo.

Sarcoma indiferenciado - Ocupava o abdome e os membros pélvicos de um canário, onde se infiltrava pelos músculos.

Adenocarcinoma de glândula sebácea - Ocupava pálpebra, olho e órbita de um camundongo, fêmea, de dois anos de idade.

Adenocarcinoma indeterminado - Ocorreu na face de um camundongo.

\section{NEOPLASIAS LOCALMENTE AGRESSIVAS}

Foram diagnosticados dois casos de tumor de células basais, localizados na vulva de um hamster fêmea e na pele de um camundongo fêmea.

\section{Discussão}

Foram encontrados dois casos de tumor de células basais, ou carcinoma basocelular, em um hamster e um camundongo. Os autores, acompanhando o pensamento atual a respeito desse tumor, tendem a vê-lo apenas como localmente agressivo. Isto reflete as opiniões contemporâneas a respeito desse tumor, por muitos considerado uma neoplasia maligna incapaz de metástase. MÜLLER et al., (1985) o consideravam benigno, e THEILEN e MADEWELL (1987) propuseram que, em vista de seu curso clínico benigno, o carcinoma basocelular fosse reclassificado como "tumor das células basais".

$\mathrm{Na}$ presente pesquisa, a neoplasia maligna mais freqüentemente diagnosticada em mamíferos foi o linfossarcoma (perfazendo, aliás, 50\% das neoplasias em hamster). Registrou-se um caso de linfossarcoma em ave (um lóris negro). $\mathrm{O}$ linfossarcoma é a neoplasia maligna mais freqüente em hamsters (WILLIAMS, 1991), podendo ser provocado pelo papilomavírus de Graffi (BARTHOLD e OLSON, 1976) ou por um viróide (WILLIAMS, 1991). Nos coelhos, o linfossarcoma é o segundo tumor em incidência (HARKNESS e WAGNER, 1993). FOX et al., (1970) apud HINTON e REGAN (1978) sugerem, como uma possível causa do linfossarcoma em coelhos, um vírus transmitido verticalmente, associado a um gene autossômico recessivo. GUPTA (1976) encontrou, em células de linfossarcoma de coelho, partículas semelhantes a vírus. O linfossarcoma tem uma alta incidência nas aves galiformes, sendo causado por vírus, e já foi descrito em falconiformes e estrigiformes (WILLIAMS, 1991). Suspeita-se que o adenocarcinoma renal dos periquitos também possa ser causado pelo vírus da leucose aviária (WILLIAMS, 1991). No presente 
trabalho, a neoplasia maligna mais freqüente em aves foi o carcinoma espinocelular. AMAND e TINKELMAN (1985) relatam a ocorrência de carcinoma espinocelular na cavidade oral de Pelecanus erythronhynchos; e FOWLER (1987) menciona a ocorrência de carcinoma espinocelular em Ara macao e Columba livia.

Quatro neoplasias em camundongo são relatadas na presente pesquisa, inclusive um hemangiossarcoma. Esta é a segunda neoplasia mais comum em camundongos fêmeas sem linhagem definida, segundo HARKNESS e WAGNER (1993). Relatou-se também um adenocarcinoma de glândula sebácea em camundongo, sendo este tipo de neoplasia pouco comum em qualquer espécie (THEILEN e MADEWELL, 1987). Na Kansas University entre 3837 cães portadores de neoplasia, encontraram-se apenas 32 casos de adenocarcinoma de glândula sebácea. Houve quatro recidivas após excisão, e nenhuma metástase foi relatada (THEILEN e MADEWELL, 1987). O adenocarcinoma de glândula sebácea já foi relatado em furão (WILLIAMS, 1991) e em coelho (PORT e SIDOR, 1978).

A maioria das neoplasias relatadas no presente trabalho, tanto em mamíferos quanto em aves, localizava-se na pele ou no tecido subcutâneo. Em cobaias essa é a segunda localização de neoplasias, em incidência (MANNING, 1976). Entre os periquitos australianos, os sítios mais comuns para localização de tumores são a pele e o tecido subcutâneo (WILLIAMS, 1991).

$\mathrm{Na}$ presente pesquisa, houve seis casos de neoplasia em hamster. A incidência de tumores em hamsters varia de acordo com a colônia estudada e com o critério de classificação histológica das lesões. ASHBEL (1945) apud HANDLER (1976) encontrou 13 neoplasias numa população de 1000 hamsters. ROBINSON (1976) cita uma colônia em que a incidência chegou perto de $100 \%$. KIRKMAN e ALGARD (1968) apud ROBINSON (1976) afirmam que algumas dessas altas taxas de incidência seriam reduzidas se se aplicasse um critério mais rígido de diferenciação entre hiperplasia e neoplasia de córtex adrenal. De modo geral, a incidência citada nos trabalhos mais antigos varia de 3 a $4 \%$, enquanto que as incidências citadas nos trabalhos modernos chegam a $40 \%$ (WILLIAMS, 1991). Isso seria devido ao fato de muitas neoplasias, nos trabalhos modernos, serem detectadas somente em seções microscópicas seriadas de órgãos (WILLIAMS, 1991). No presente trabalho, havia registro de que um dos hamsters com linfossarcoma apresentava diarréia crônica. Diarréia, pielonefrite e infertilidade costumam fazer parte da síndrome paraneoplásica do linfossarcoma em hamsters (WILLIAMS, 1991) e, aliás, em muitos outros animais.

Relatou-se, na presente pesquisa, uma neoplasia (tricoepitelioma) em cobaia. A incidência de neoplasias em cobaias é baixa (MANNING, 1976; WILLIAMS, 1991; HARKNESS e WAGNER, 1993). SHIMKIN e MIDER (1940) apud MANNING (1976) não observaram nenhuma neoplasia em 15000 cobaias examinadas entre 1916 e 1937. PAPANICOLAOU e OLCOTT (1942) apud MANNING (1976) necropsiaram 7000 cobaias e encontraram apenas 100 neoplasias. MOSINGER (1961) apud MANNING (1976) registrou cinco neoplasias após 5540 necropsias. Entretanto, segundo EDIGER, KOVATCH e RABSTEIN (1974) apud MANNING (1976), a incidência após os três anos pode chegar a 30\%, e segundo MANNING (1976) as neoplasias mais comuns são as do trato respiratório, seguidas pelas de pele e tecido subcutâneo. MANNING (1976) fez uma ampla revisão bibliográfica dos relatos de neoplasia em cobaia de 1876 a 1974, e menciona um único relato de tricoepitelioma, feito por HARANGHY et al., em 1954. O plasma de cobaia tem propriedades inibidoras do crescimento tumoral, conhecidas desde os trabalhos de KIDD, em 1953 (MANNING, 1976). Parece que o fator antitumoral das cobaias é a asparaginase (WILLIAMS, 1991).

Quanto aos primatas, segundo WILLIAMS (1991), a literatura enfatiza a baixa incidência de tumores espontâneos nesses animais. Isto seria devido, na verdade, à pouca idade dos primatas usados em pesquisa (WILLIAMS, 1991). Fibromas foram descritos na conjuntiva de Cercopithecus aethiops sabaeus por WADWORTH (1953) apud O'GARA e ADAMSON (1972) e no epíplo de Papio comatus por FOX (1936) apud O'GARA e ADAMSON (1972).

A maioria das aves que figuram na presente pesquisa são psitaciformes e passeriformes oriundos de cativeiro doméstico. PETRAK e GILMORE (1982) apud WILLIAMS (1991) afirmam que as neoplasias são responsáveis por 20 a $30 \%$ das mortes dos psitaciformes e passeriformes que vivem em cativeiro doméstico. Os periquitos australianos apresentam uma incidência particularmente alta, de 15\% (WILLIAMS, 1991). O tipo histológico mais comum é o lipoma, associado a sedentarismo, superalimentação e hipotiroidismo subclínico provocado por baixos teores de iodo na dieta (WILLIAMS, 1991). Tumores gonadais também são comuns nos periquitos australianos, e provocam mudança na cor da carúncula, em machos, e alterações de comportamento (WILLIAMS, 1991). 


\section{REFERÊNCIAS BIBLIOGRÁFICAS}

AMAND, W. B.; TINKELMAN, C. L. Oral disease in captive wild animals. In: HARVEY, C. E. Veterinary dentistry. Philadelphia: W. B. Saunders, 1985.

BARTHOLD, S.W.; OLSON, C. Viral neoplastic diseases. IX. Papovavirus induced neoplasia. In: MELBY, E.C.; ALTMAN, N. H. CRC Handbook of laboratory animal science. CRC Press, 1976.

FOWLER, M.E. Zoo animals and wildlife. In: THEILEN, G. H.; MADEWELL. B. R. Veterinary cancer medicine. 2. ed. Philadelphia: Lea \& Febiger, 1987.

GUPTA, B. N. Lymphosarcoma in a rabbit. Am. J. Vet. Res. 37:841-843, 1976.

HARKNESS, J. E.; WAGNER, J. E. Biologia e clínica de coelhos e roedores. 3.ed. São Paulo: Roca, 1993.

HANDLER, A. H. Disease of laboratory animals neoplastic, transplantable tumors. In: MELBY, E.C.; ALTMAN, N. H. CRC Handbook of laboratory animal science. CRC Press, 1976.

HINTON, M.; REGAN, M. Cutaneous lymphosarcoma in a rabbit. Vet. Rec. 103:140-141, 1978.
MANNING, P. J. Neoplastic diseases. In: WAGNER, J. E.; MANNING, P. J. The biology of guinea pig. Academic Press, 1976.

MÜllER, G. H.; KIRK, R. W.; SCOTT, D. W. Dermatologia dos pequenos animais. 3. ed. São Paulo: Manole, 1985.

O'GARA, R. W., ADAMSON, R. H. Spontaneous and induced neoplasms in nonhuman primates. In: FIENNES, R. N. T. W. Pathology of simian primates. Part I. General pathology. Basel: S. Karger, 1972.

PORT, C. D., SIDOR, M. A. A sebaceous gland carcinoma in a rabbit. Lab. An. Sci. 28: 215, 1978.

ROBINSON, F.R. Naturally ocurring neoplastic diseases - III - Hamster. In: MELBY, E.C., ALTMAN, N. H. CRC Handbook of laboratory animal science. CRC Press, 1976.

THEILEN, G. H., MADEWELL, B. R. Tumors and tumorlike conditions of epithelial origin, In: THEILEN, G. H., MADEWELL. B. R. Veterinary cancer medicine. 2. Ed. Philadelphia: Lea \& Febiger, 1987.

WILLIAMS, D. L. Tumors of laboratory mammals, birds and exotic animals. In WHITE, R. A. S. Manual of small animal oncology. BSAVA, Grã-Bretanha, 1991. 